\title{
DUAS OU TRÊS COISAS SOBRE ANTONIO CANDIDO
}

Ricardo MUSSE ${ }^{1}$

- RESUMO: Busca-se aqui investigar a conexão entre duas características definidoras da originalidade crítica de Antonio Candido: sua filiação à linhagem do "marxismo ocidental" e sua inserção numa tradição nacional.

- PALAVRAS-CHAVE: Crítica; literatura; vida social; tradição nacional; dialética; marxismo ocidental.

Num artigo destinado a ressaltar a originalidade da crítica de Antonio Candido, tomando como ponto de partida os estudos desse autor sobre O Cortiço, Roberto Schwarz insere-o em dois sistemas conceituais distintos.

Primeiro, Schwarz associa-o à corrente que procura "demonstrar pelo exemplo a legitimidade e até a necessidade do trânsito entre análise estética e reflexão social, um vaivém de esquerda" (Schwarz, 1992b, p.31).

Ora, a inseparabilidade entre materiais estéticos e sociais, expressa no lema de Antonio Candido "filiação de textos e fidelidade a contextos" - que lhe permite fazer não apenas uma sondagem da correspondência estrutural entre literatura e vida social, mas também ampliar os conhecimentos existentes acerca da realidade externa, precisamente pelo estudo do dinamismo literário -, esta reversibilidade entre análise literária e análise social, sabe-se bem, constitui uma das premissas do campo teórico e conceitual do "marxismo ocidental". ${ }^{2}$

1 Professor do Departamento de Filosofia da UNESP - 17525-900 - Marília - SP - Brasil.

2 Essa associação, como o próprio marxismo ocidental, inicia-se com História e consciência de classe. Numa passagem célebre, Georg Lukács a expressa, de forma ainda tosca, nos seguintes termos: "A história dos problemas estudados torna-se efetivamente uma história dos problemas. A expressão literária ou científica de um problema aparece como expressão de uma totalidade social, como expressão das suas possibilidades, dos seus limites e dos seus problemas. O estudo histórico da literatura sobre os problemas é assim o que melhor pode exprimir a problemática do processo histórico. A história da filosofia torna-se filosofia da história". (Lukács, 1974, p.49) 
Logo em seguida, Schwarz atribui a peculiaridade desse percurso às necessidades da crítica em países periféricos. Assim, “... o compacto heterogêneo de relações histórico-sociais que a forma sempre articula, e que faz da historicidade, a ser decifrada pela crítica, a substância mesma das obras" (p.36), remete-nos a uma configuração histórica e política especial: a experiência social brasileira. Na verdade, mais do que a situação perante o mercado mundial, o que parece essencial aqui não é o conceito de periferia, mas o de "âmbito e ordem nacional". Tanto assim que, logo após situar Candido no enfrentamento literário-político-ideológico acerca da especificidade da sociedade brasileira, Schwarz avalia seus novos escritos na seguinte chave:

\begin{abstract}
passados os anos, o valor de seus escritos - que melhoram e ganham saliência com o tempo parece trocar de origem: interessam justamente por não se esgotarem no universalismo prêt-àporter do debate teórico atual, ou melhor por terem continuidade refletida com as posições, noções e contradições sustentadas pela experiência histórica do país, dentro, fora e antes da universidade, cujo andamento é outro possivelmente mais real. (Idem, p.39) ${ }^{3}$
\end{abstract}

Preocupado em estabelecer as coordenadas da idéia social de forma literária e, a partir daí, em contestar metodologias atualmente em voga, Schwarz pouco nos esclarece, aqui, acerca deste sistema de idéias nacionais em que insere Antonio Candido, ou ainda, acerca dessa conjunção inusitada de "marxismo ocidental", universalista por princípio, e de "sistema nacional".

Noutro texto, porém, nas notas do debatedor a uma exposição de Paulo Arantes centrada no conceito de formação, Schwarz explicita melhor o que seria este "sistema nacional". ${ }^{4}$ Seguindo um raciocínio análogo ao utilizado por Antonio Candido em Formação da Literatura Brasileira, isto é, identificando a noção de tradição com a formação de um sistema, caracterizado pela interação entre autores, obras e público, Schwarz aponta, nas entrelinhas do seu texto, para o amadurecimento, na obra de Antonio Candido, de um sistema crítico brasileiro.

Nessa tradição, Candido ocupa um lugar semelhante ao de Machado de Assis na formação do nosso sistema literário. A excelência de suas análises seria uma garantia a mais em favor da tese de que um ciclo acumulativo se completou. Se o caráter realizado da formação literária, objeto de sua análise, permitiu a Candido, por exemplo, se diferenciar de obras capitais da cultura brasileira - particularmente dos livros de Gilberto Freyre, Sérgio Buarque, Caio Prado e Celso Furtado -, impregnadas por desejos e juízos de valor, por outro lado, o caráter de fato desta formação

3 Ao indagar, noutro texto, acerca do espaço histórico da crítica de Antonio Candido, Schwarz a define como voltada para a compreensão de um processo que não é nacional (pois se trata dos movimentos do capital), mas destaca também que a comparação entre tradições literárias distintas, sempre presente nas análises de Candido, “... supõe histórias nacionais separadas, no quadro de um concerto de nações independentes, cujas diferenças seriam a riqueza da humanidade. A historiografia que lhe corresponde seria nacional, ainda que não nacionalista". (Schwarz, 1989b, p.152-3)

4 Cf. Schwarz, 1992a. 
possibilitou, na opinião de Schwarz, que Antonio Candido tratasse de um tema eminentemente nacional com o distanciamento de um "internacionalista convicto". Assim, a especificação dos vícios e das virtudes peculiares a esse processo cumulativo, não só afasta Candido da orientação patriótica, típica do nacionalismo tacanho, como também gera, pela constituição de um sistema local de problemas e contradições isto é, pela formação de um campo de forças históricas que atua como uma espécie de filtro -, uma barreira à ilusão universalista. As questões contemporâneas seriam então "filtradas", ou melhor, inseridas apenas como momentos ou faces de um campo local. Esta moderação, a incorporação meditada e contextualizada de teorias, seria, nesta versão, o sintoma maior de que a literatura, a crítica, a filosofia alcançaram a almejada maturidade.

Embora essa reconstrução - seja do alcance teórico de Formação da Literatura Brasileira, seja destas novas séries cumulativas que se organizam como sistema possa ser objeto de controvérsias, parece inegável que o ponto de partida tomado por Roberto Schwarz é correto: Antonio Candido insere-se, como um momento particularmente feliz, na tradição do "pensamento nacional".

Aliás, essa afirmação assenta-se - e corrobora - numa série de asserções, de tentativas de autocompreensão, que o próprio Candido fez, em textos e momentos diversos, acerca de sua obra. Segundo ele, a consolidação teórica de seu percurso intelectual baseia-se em três fontes concomitantes: o modernismo definido, no sentido amplo, como o movimento cultural brasileiro de entre guerras (Candido, 1980, p.134):5 o ensaio histórico-sociológico - decorrente tanto da influência do espírito modernista, do "ímã literário", quanto do "sopro de radicalismo político intelectual que eclodiu depois da Revolução de 30" -, de Casa grande e senzala, de Raízes do Brasil e de Formação do Brasil Contemporâneo, em que confluem história e economia, filosofia e arte, numa "forma bem brasileira de investigação e descoberta do Brasil"; 6 e a nova mentalidade definida pela Faculdade de Filosofia da Universidade de São Paulo.?

Trata-se de um corte horizontal que privilegia os anos de formação intelectual de Antonio Candido, ancorados na década de 1930. A cada ponto dessa lista

5 "O Modernismo nos interessava sobretudo como atitude mental, ao contrário de hoje, quando interessa mais como criação de uma linguagem renovadora. Para nós, esta era veículo. Veículo da atitude de renovação crítica do Brasil, do interesse pelos problemas sociais; do desejo de criar uma cultura local com os ingredientes tomados avidamente aos estrangeiros" (Candido, 1978, p.187). Acerca da herança modernista na obra de Antonio Candido, cf. tb. Arrigucci, 1992, p.183-6

6 Cf. Candido, 1980, p.130; 1992, p.124. Casa grande e senzala, bem como a série iniciada por essa obra, são, nas palavras de Antonio Candido, “...uma ponte entre o naturalismo dos velhos intérpretes da nossa sociedade como Silvio Romero, Euclides da Cunha e mesmo Oliveira Viana, e os pontos de vista mais especificamente sociológicos que se imporiam depois de 1940".

7 A Revista Clima foi, segundo Candido, a primeira manifestação no terreno da critica e do movimento das idéias dessa nova mentalidade. Muitas atitutes dessa geração provêm não de próceres que depois tornaram-se ilustres como Lévy-Strauss e F. Braudel, mas do quase obscuro, em nossos dias, professor Jean Maugüé. Cf. Candido, 1978; Arantes, 1989. 
corresponde, porém, uma série submersa que se estende do passado ao presente. A vocação para refletir e se interessar pelo Brasil, intensificada por motivos vários neste decênio, data - na periodização do próprio Candido - de muito antes, mais precisamente do Romantismo, tendo inclusive, antes do seu ápice no Modernismo, um ponto alto no Naturalismo. ${ }^{8}$

Essas tentativas de autodefinição e diferenciação, a própria vocação nativista, teriam como ponto comum inevitável a constatação de particularidades de meio, raça e história que nem sempre correspondem aos padrões europeus propostos pela educação. $O$ transplante de culturas, o implante de um modelo universalista em nosso meio, típicos dos processos de colonização e de dependência, se, por um lado, nos inserem no conjunto da cultura ocidental, por outro lado, chocam-se com elementos divergentes e aberrantes. Esta dupla filiação, à herança européia e ao anseio de exprimir uma sociedade diferente em muitos aspectos da européia, levou muitos de nossos escritores e pensadores a descrever o Brasil como um país de contrastes. ${ }^{9}$

Tal senso dos contrastes, a apresentação das histórias do homens e das instituições em virtude de condições antagônicas, insere-se, segundo Antonio Candido, numa lei mais geral da nossa cultura, a dialética do local e do cosmopolita: "Se fosse possível estabelecer uma lei de evolução da nossa vida espiritual, poderíamos talvez dizer que toda ela se rege pela dialética do localismo e do cosmopolitismo" (Candido, 1980, p. 109). ${ }^{10}$

Esta lei genérica não é, entretanto, um pressuposto apriorístico ou um axioma intuitivo adotado por Antonio Candido como ponto de partida. Ela é o resultado de infindáveis pesquisas, dito de outro modo, trata-se de uma descoberta crucial acerca da especificidade brasileira.

Assim, quando Candido se debruçou sobre a formação da nossa literatura compreendendo por literatura um sistema orgânico de obras ligadas por uma interação dinâmica em torno do triângulo "autor-obra-público" numa continuidade literária ${ }^{11}$ -

8 “Em crítica literária, a fase 1880-1900, por suas três principais figuras - Sílvio Romero, Araripe Júnior e José Veríssimo - havia desenvolvido e apurado a tendência principal do nosso pensamento crítico, isto é, o que se poderia chamar a crítica nacionalista, de origem romântica", ou ainda: "pode-se dizer que o Modernismo veio criar condições para aproveitar e desenvolver as intuições de um Sílvio Romero, ou um Euclides da Cunha, bem como as pesquisas de um Nina Rodrigues" (Candido, 1980, p.115, 123).

9 Tal regra, segundo Antonio Candido, aplica-se de modo geral ao pensamento latino-americano, cf. Candido, 1992, p.127.

10 "Pode-se chamar dialético a este processo porque ele tem realmente consistido numa integração progressiva de experiência literária e espiritual, por meio da tensão entre o dado local (que se apresenta como substância da expressão) e os moldes herdados da tradição européia (que se apresentam como forma da expressão)" (Candido, 1980, p.110)

11 Candido distingue literatura de manifestações literárias pela presença sistemática de três fatores concomitantes: "a existência de um conjunto de produtores literários, mais ou menos conscientes do seu papel; um conjunto de receptores, formando os diferentes tipos de público, sem os quais a obra não vive; um mecanismo transmissor, (de modo geral, uma linguagem, traduzida em estilos), que liga uns a outros" (Candido, 1975, v.1, p.23). Essa continuidade ininterrupta de obras e autores gera uma tradição literária que ele define assim: "é uma tradição, no 
tomou como dado primário o vínculo placentário de nossa literatura com as literaturas européias. Tal fato, antes uma decorrência natural do nosso processo histórico do que fruto de uma opção - expresso na célebre frase "a nossa literatura é galho secundário da portuguesa, por sua vez arbusto de segunda ordem no jardim das Musas..." (Candido, 1975, v.1, p.9) -, faz que o estudo da literatura brasileira não possa se eximir da análise de seus caracteres próprios, ou melhor, da relação que mantém com outras literaturas. Essa constatação conduziu Antonio Candido a ponderar acerca da relação inevitável entre formas importadas e a escolha de temas novos ou a adoção de sentimentos diferentes, de tal modo que não teve como deixar de "estudar a formação da literatura brasileira como síntese de tendências universalistas e particularistas" (p.23).

Esse andamento dual se intensifica pela disposição dos brasileiros de inserir o projeto de constituição de uma literatura própria no esforço de construção do país. O programa do "nacionalismo artístico", o compromisso de uma literatura empenhada, visa a diferenciação e particularização de temas e modos de exprimi-los. Nesse sentido, num livro que se propõe a ser a "história dos brasileiros em seu desejo de ter uma literatura", nada mais natural que o "jogo destas forças, universal e nacional, técnica e emocional, que plasmaram (nossa literatura) como permanente mistura da tradição européia e das descobertas do Brasil" (Idem, p.28) ocupe o lugar central.

Mais ainda, a reinterpretação local das orientações estéticas e filosóficas hauridas no exemplo europeu torna-se a chave que permite organizar, de modo abrangente, as linhas mestras do processo de formação da literatura brasileira como sistema. ${ }^{12}$ Esse processo define a articulação entre os "momentos decisivos" - Arcadismo e Romantismo - de tal modo que, apesar da evidente ruptura estética, torna-se possível determinar, ao longo do período entre 1750 e 1880, uma continuidade. Esta solidariedade estreita entre movimentos estéticos diversos, aproximados pela vocação histórica - um dos pressupostos da Formação -, se dá pela via de uma complementaridade: o Arcadismo incorpora o Brasil aos padrões europeus tradicionais, ao sistema expressivo da literatura ocidental, possibilitando ao Romantismo, com sua ênfase nos elementos locais, se apresentar, ao mesmo tempo, como nacional e universal. Esta associação, as semelhanças e os contrastes entre esses estilos literários, esclarece-se melhor quando Candido a exemplifica tendo em vista a temática indianista:

Na medida em que toma uma realidade local para integrá-la na tradição clássica do Ocidente, o indianismo inicial dos neoclássicos pode ser interpretado como tendência para dar

sentido completo do termo, isto é, transmissão de algo entre os homens, e o conjunto de elementos transmitidos, formando padrões que se impõem ao pensamento ou ao comportamento, e aos quais somos obrigados a nos referir para aceitar ou rejeitar" (p.24).

12 Cf. Candido, 1975, p.72. Segundo Antonio Candido, "quatro grandes temas presidem à formação da literatura brasileira como sistema entre 1750 e 1880, em correlação íntima com a elaboração de uma consciência nacional: o conhecimento da realidade local; a valorização das populações aborígines; o desejo de contribuir para o progresso do país; a incorporação aos padrões europeus" (idem., ibid.). 
generalidade ao detalhe concreto. ... O indianismo dos românticos, ao contrário, denota tendência para particularizar os grandes temas, as grandes atitudes de que se nutria a literatura ocidental, inserindo-as na realidade local, tratando-as como próprias de uma realidade brasileira. (Candido, 1975, v.2, p.21)

Ora, Antonio Candido não extraiu esta regra geral, a dialética do local e do cosmopolita apenas dos seus estudos acerca da formação da literatura brasileira. Percebeu-a também como característica decisiva da crítica literária e mesmo das tentativas de interpretação do Brasill. ${ }^{13}$

Concomitantemente às suas análises literárias, Candido escreveu uma série de artigos e também livros que pode muito bem ser reconstruída como uma história meditada da reflexão crítica brasileira, ${ }^{14}$ o que talvez nos ajude a entender porque, na definição precisa de Davi Arrigucci Júnior, a sua obra

assume uma função decisiva no contexto brasileiro, em seu movimento a uma só vez de herança e passagem, um ponto privilegiado da lucidez critica e da consciência histórica com relação à tradição. No arcabouço articuladíssimo de sua construção, permanece e se renova a problemática central organizada pela melhor crítica brasileira ao longo dos anos: dos românticos, de Machado de Assis, de Sílvio Romero, de José Verissimo, de Araripe Jr., do legado modernista, da crítica militante dos anos 30 e 40. (Arrigucci, 1992, p.186)

O mal-estar gerado pelo caráter imitativo de nossa vida cultural - o "sentimento de contradição entre a realidade nacional e o prestígio dos países que nos servem de modelo" (Schwarz, 1989a, p.30) -, a tensão entre o esforço de atualização e de desprovincianização, e o desejo de retomar criticamente o trabalho dos predecessores marcam também, na visada lúcida de Antonio Candido, não só a nossa tradição crítica e interpretativa, mas as próprias dificuldades com que se defronta, ainda hoje, o trabalho intelectual levado a cabo no Brasil. Assim, não nos parece ser nenhuma impropriedade a generalização dessa dialética, levada a cabo por Antonio Candido, para toda a vida mental brasileira. ${ }^{15}$

13 Segundo Paulo E. Arantes, Antonio Candido deriva o seu conceito de formação não da noção de tradição de T. S. Eliot - como alegam alguns de seus discípulos perante os quais o próprio Candido teria, para efeito de ilustração didática, se referido ao célebre "Tradition and the individual talent" -, mas do campo interno produzido pela tematização brasileira da questão: "... formado na escola de Machado de Assis, de fato Antonio Candido aprendeu mesmo foi com as falhas de formação dos predecessores cujos achados modestos também soube fixar e sublimar", isto é, "ajustou-se antes de tudo pela lição de Sílvio Romero e José Verissimo, naturalmente revista e corrigida" (Arantes, 1992a, p.240).

14 Arantes noticia: " ... o projeto de um conjunto de estudos sobre a crítica literária brasileira, planejado por Antonio Candido no âmbito da disciplina de teoria literária da Universidade de São Paulo, uma outra história dos brasileiros cultivados de, no seu desejo de ter uma crítica literária, também contribuir para formar a cultura nacional". Alinham-se aí, de certo modo, neste esforço de reconstrução do processo formativo de nossa crítica, além de uma série de teses defendidas sob a orientação de Candido, a tese de 1945 - O método crítico de Sílvio Romero -, bem como os artigos "Fora do texto, dentro da vida", "O ato crítico" etc.

15 Acerca do problema da dependência cultural, examinado à "luz da reflexão sobre o atraso e o subdesenvolvimento" cf. Candido, 1976b. Arantes nos lembra também que a "dialética do local e do universal - a alternância de 
Na descrição sintética de Roberto Schwarz - para Antonio Candido, "a originalidade nacional existe, e existe como processo e parte da cena contemporânea, e não como ponto de honra pátrio, compêndio provinciano de aspectos pitorescos ou tautologia" (Schwarz, 1989b, p.137). ${ }^{16}$

Nesta chave, Antonio Candido concebe uma solução própria para a oposição universal-nacional, que perpassa a cultura brasileira: a integração coerente dos termos assemelha-se a um movimento entre os pólos, em que nenhuma parte é privilegiada ou imposta como decisiva. ${ }^{17}$

A especificidade brasileira, a dialética do local e do cosmopolita, serve então ao próprio Antonio Candido como uma ponta de lança privilegiada para inserir a sua tarefa crítica nos quadros do marxismo ocidental. A vocação universalista da análise das conseqüências do predomínio da forma mercadoria no âmbito do sistema capitalista adquire um matiz particular, associando-se, em países como o nosso, com o estudo de uma vida intelectual singular, o que não deixa de ter conseqüências para o marxismo ocidental como um todo. Doravante, a reversibilidade entre análise literária e análise social incorpora não apenas novas tradições culturais, mas também assenta-se num ponto de vista inusitado: o sistema mundial de troca de equivalentes passa a ser revisitado da periferia, a partir de domínios excluídos e prejudicados, 0 que contribui para afiar ainda mais a crítica da sociedade capitalista.

MUSSE, R. Two or three things about Antonio Candido. Trans/Form/Ação (São Paulo), v.18, p.43-50, 1995.

- ABSTRACT: The aim of this paper is to discuss the connection between two basic traces grounding the originality of Antonio Candido's literary criticism: firstly, its insertion into the mainstraim of "western marxism" and, secondly, into national (Brasilian) tradition.

- KEYWORDS: Literary criticism; literature; social life; national tradition; dialectics; western marxism.

complementaridade, divergência e equilibrio entre essas tendências exprime não só a lógica específica do sistema literário brasileiro, mas também a regra geral de certas linhas evolutivas de nossa sociedade a que o ensaio clássico de interpretação do Brasil deu o nome de Formação" (Arantes, 1992b, p.17).

16 Schwarz nos alerta que: "assim, o acento no caráter nacional da originalidade literária, que de diferentes modos foi bandeira ideológica e estética de românticos, modernistas e outros, está de sentido mudado. Corresponde a uma constatação, ligada aliás, no caso, a aspectos da realidade relativamente originais eles também, mas de que não há porque se orgulhar, tais como a anomia social que acompanha a escravatura. Depois de ser um valor patriótico inquestionado, que pede reconhecimento e adesão, a singularidade nacional é agora um fato da vida, e pede espírito crítico" (Schwarz, 1989b, p.134-5).

17 Davi Arrigucci Jr. rastreia, em seu ensaio "Movimentos de um leitor", diversos aspectos dessa pendularidade. 


\section{Referências bibliográficas}

1 ARANTES, P. E. Certidão de nascimento. Novos Estudos, n.23, mar. 1989.

2 _. Providências de um crítico literário na periferia do capitalismo. In: Dentro do texto, dentro da vida, ensaios sobre Antonio Candido. São Paulo: Companhia das Letras, 1992a. p.229-61.

3 _. Sentimento da dialética na experiência intelectual brasileira. São Paulo: Paz e Terra, 1992b.

4 ARRIGUCCI JÚNIOR, D. Movimentos de um leitor. In: Dentro do texto, dentro da vida, ensaios sobre Antonio Candido. São Paulo: Companhia das Letras, 1992. p.181-204.

5 CANDIDO, A. Formação da literatura brasileira. 5.ed. Belo Horizonte: Itatiaia, São Paulo: Edusp, 1975. v.1, 2.

6 L Literatura e cultura de 1900 a 1945. In: Literatura e Sociedade. São Paulo: Companhia Editora Nacional, 1980. p.109-38.

7 _. Depoimento sobre Clima. Discurso, n.8, p.183-93, maio 1978.

8 . Fora do texto, dentro da vida. In: Educação pela noite \& outros ensaios. São Paulo: Ática, 1987a. p.140-62.

9 L Literatura e subdesenvolvimento. In: Educação pela noite \& outros ensaios. São Paulo: Ática, 1987b. p.140-62.

10 . O ato crítico. In: Educação pela noite \& outros ensaios. São Paulo: Ática, 1987c. p. $140-62$.

11 O método crítico de Sílvio Romero. São Paulo: Edusp, 1988.

12 . Raízes do Brasil. In: Teresina etc. São Paulo: Paz e Terra, 1992. p.123-38.

13 LUKÁCS, G. Histónia e consciência de classe. Porto: Publicações Escorpião, 1974.

14 SCHWARZ, R. Nacional por subtração. In: Que horas são? São Paulo: Companhia das Letras, 1989a. p.29-48.

15 _ Pressupostos, salvo engano, de Dialética da malandragem. In: Que horas são? São Paulo: Companhia das Letras, 1989b. p.129-55.

16 . Notas do debatedor. In: Dentro do texto, dentro da vida, ensaios sobre Antonio Candido. São Paulo: Companhia das Letras, 1992a. p.262-7.

17 _. Originalidade da crítica de Antonio Candido. Novos Estudos, n.32, p.31-46, março 1992b. 